\title{
Endothelin-I Serum Concentration in Pediatric Chronic Idiopathic Uveitis
}

This article was published in the following Dove Press journal:

Clinical Ophthalmology

\section{Katarzyna Powierza (D) \\ Jolanta Sawicka- \\ Powierza (iD ${ }^{2}$ \\ Beata Urban (1D ${ }^{3}$ \\ Beata Żelazowska- \\ Rutkowska (iD) ${ }^{4}$ \\ Bogdan Cylwik (1D) \\ Bożena Mikołuć (iD ${ }^{5}$ \\ Olga Kowalewska ${ }^{6}$ \\ Alina Bakunowicz- \\ Łazarczyk $^{3}$}

'University Clinical Hospital in Bialystok, Medical University of Bialystok, Bialystok 15-276, Poland; ' 2 Department of Family Medicine, Medical University of Bialystok, Bialystok 15-054, Poland; ${ }^{3}$ Department of Pediatric Ophthalmology and Strabismus, Medical University of Bialystok, Bialystok 15-274, Poland; ${ }^{4}$ Department of Pediatric Laboratory Diagnostics, Medical University of Bialystok, Bialystok 15-274, Poland; ${ }^{5}$ Department of Pediatrics, Rheumatology, Immunology and Metabolic Bone Diseases, Medical University of Bialystok, Bialystok 15-274, Poland; ${ }^{6}$ Psychiatric Clinic, Lund, Division of Psychiatry, Lund 222 40, Sweden

Correspondence: Jolanta SawickaPowierza

Department of Family Medicine, Medical

University of Bialystok, Mieszka I 4B

Street, Bialystok 15-054, Poland

Tel +48857326820

$\mathrm{Fax}+48857327848$

Email jolasawicka@gmail.com
Purpose: The aim of our study was to determine endothelin-1 (ET-1) concentration in chronic idiopathic uveitis in children and adolescents depending on anatomical location and grade of inflammation.

Methods: The cross-sectional study was conducted among 17 patients with chronic idiopathic uveitis and 22 healthy controls. Concentration of ET-1 in serum was determined using a commercially available ELISA kit. The concentration of $\mathrm{C}$ reactive protein (CRP) in serum was determined by immunoturbidimetric method using CRP4 reagent kit (Roche Diagnostics GmbH, Mannheim, Germany).

Results: Statistically significant difference between ET-1 concentration in patients with chronic idiopathic uveitis and controls was found $1.33(1.22 ; 1.48)$ vs $1.93(1.1 ; 3.11), p=$ 0.008). No correlations were found between ET-1 concentration and age, either in chronic idiopathic uveitis patients or controls. Nine out of 17 patients presented with anterior uveitis, 5 with posterior and 3 with panuveitis. There were no differences in ET-1 concentration between anterior, posterior and panuveitis $(p=0.634)$, and in terms of grade of inflammation. Conclusion: ET-1 expression is disturbed in pediatric chronic idiopathic uveitis irrespective of the anatomical location and grade of inflammation. Lower expression of ET-1 plays a crucial role in disturbed vascular tone control and can result in permanent visual impairment in chronic non-infectious uveitis.

Keywords: adolescents, children, chronic idiopathic uveitis, endothelin-1

\section{Introduction}

Uveitis is the inflammation of the uveal tract which lines the inside of the eye behind the cornea. Much of the uvea lies between the retina and tough, outer sclera. The uveal tract consists of three parts: the iris, the ciliary body and the choroid. ${ }^{1,2}$ Left untreated, uveitis can cause serious complications including cataracts, glaucoma, macular edema, retinal detachment, retinal scarring, optic nerve damage or even permanent vision loss. Uveitis is categorized according to the affected part of the uveal tract. There are three anatomical patterns of uveitis. Anterior uveitis (most common) affects the inside of the front of the eye (between the cornea and the iris) and the ciliary body. Intermediate uveitis affects the retina and blood vessels just behind the lens (pars plana). Posterior uveitis affects the choroid as well as the retina. Panuveitis affects all structures of the uvea.

Uveitis can occur in any age group, but pediatric uveitis differs from adult-onset uveitis. $^{3,4}$ In a population-based study in the United Kingdom and Finland, the annual incidence rate of uveitis was found to be 3.5 to 4.3 per 100,000 children, respectively. ${ }^{5,6}$ Uveitis in children is very often asymptomatic, chronic and resistant to treatment. In 
most cases of pediatric uveitis, anterior uveitis and up to $60 \%$ idiopathic cases are diagnosed. Pediatric rheumatological diseases associated with uveitis include juvenile idiopathic arthritis, juvenile sarcoidosis/Blau syndrome and Behçet's disease. $^{3,4,7-9}$ A large percent of patients with uveitis have a disease that does not fit into any known etiologic category. ${ }^{10,11}$ Many patients with this disorder, have a form of sarcoid limited to the eye, ${ }^{12}$ some viral infections ${ }^{13}$ or other autoimmune reactions. A huge challenge for ophthalmologists around the world is pediatric idiopathic non-infectious uveitis, where the triggering factors are still unknown.

ET-1, a very strong vasoconstrictor peptide, is widely distributed in human tissues and secreted mainly by vascular smooth muscle cells (VSMC). As a result of transcription, proendothelin-1 is formed, and subsequent stimulation by hypoxia or vascular wall shear stress, with the participation of an endothelin converting enzyme, leads to the formation of an active peptide. ${ }^{14}$ ET-1 exerts its effects by binding to the endothelin receptors A (ETA) and B (ETB), two cell surface proteins that belong to the G-proteincoupled receptors superfamily. ETA receptors are located mostly in VSMC, where they are responsible for potent vasoconstriction, cell proliferation and a proinflammatory effect. ETB receptors include two subtypes: ETB1, which is expressed on endothelial cells and results in nitric oxidemediated vasodilation, and ETB2, present in VSMC, which causes vasoconstriction. ${ }^{15,16}$ ET-1 modulates pericyte contractility to regulate retinal blood flow and is involved in the regulation of intraocular pressure and aqueous humor dynamics. ${ }^{17,18}$ ET-1 is also an important mediator in ocular inflammatory reactions via arachidonic acid cascade. ${ }^{19}$

There are numerous literature reports on the significance of ET-1 concentration in uveitis associated with rheumatological diseases $^{20}$ or induced animal models of uveitis. ${ }^{19,21-23}$ The physiological importance of ET-1 level in blood flow in different parts of the uvea and in inflammatory process is well established, but ET-1 level in chronic non-infectious uveitis has not been established to date. Therefore, the aim of our study was to determine ET-1 concentration in chronic idiopathic uveitis in children and adolescents depending on anatomical location and the grade of inflammation.

\section{Materials and Methods}

\section{Participants}

The cross-sectional study was conducted among children and adolescents with chronic idiopathic uveitis and healthy controls, who were consecutively selected in order of appearance at the Department of Pediatric Ophthalmology and Strabismus, Medical University of Bialystok, Poland. The diagnosis of chronic uveitis and the grade of inflammation was based on clinical signs and location of the inflammatory process which was established on the basis of a slit-lamp and dilated fundus examination (anterior chamber cells, anterior chamber flare, vitreous haze, choroidal/retinal changes) according to the Standardization of Uveitis Nomenclature (SUN) and the National Eye Institute Criteria (Table 1). ${ }^{1,24,25}$ The diagnosis of idiopathic uveitis was established following an in-depth patient interview, a thorough ophthalmological and rheumatological examination and exclusion of all possible etiologies including evolving systemic conditions. Exclusion criteria were any systemic inflammatory diseases, arterial

Table I Grading Schemes for Uveitis According to SUN and the National Eye Instiute Criteria

\begin{tabular}{|l|l|}
\hline \multicolumn{2}{|l|}{ Grading Scheme for Anterior Chamber Cells } \\
\hline Grade & Cells in Field (I X I mm slit beam) \\
\hline 0 & $<$ I \\
$0.5+$ & $1-5$ \\
$1+$ & $6-15$ \\
$2+$ & $16-25$ \\
$3+$ & $26-50$ \\
$4+$ & $>50$ \\
\hline Grading Scheme for Anterior Chamber Flare \\
\hline Grade & Description \\
\hline 0 & None \\
\hline+ & Faint \\
$2+$ & Moderate (iris and lens details clear) \\
$3+$ & Marked (iris and lens details hazy) \\
$4+$ & Intense (fibrin or plastic aqueous) \\
\hline Grading Scheme for Vitreous Haze \\
\hline Grade & Description (clinical finding) \\
\hline 0 & Nil (none) \\
\hline & Minimal (posterior pole clearly visible) \\
2 & Mild (posterior pole details slightly hazy) \\
3 & Moderate (posterior pole details very hazy) \\
4 & 5 Severe (fundal details not visible) \\
\hline
\end{tabular}

Notes: Data from Nussenblatt et al..$^{24,25}$ Reproduced from Standardization of Uveitis Nomenclature (SUN) Working Group. Standardization of uveitis nomenclature for reporting clinical data. Results of the First International Workshop. Am J Ophthalmol. 2005; 140(3):509-516. Copyright 2005, with permission from Elsevier.' Adapted with permission of Touch Medical Media, from Zierhut M, Deuter C, Murray Fl. Classification of Uveitis - Current Guidelines. European Ophthalmic Review. Copyright 2007, permission conveyed through Copyright Clearance Center, Inc. ${ }^{25}$

Abbreviation: SUN, the Standardization of Uveitis Nomenclature. 
hypertension, diabetes mellitus, kidney diseases, hyperthyroidism, any ocular diseases or use of any systemic medication (eg, steroids, nonsteroidal anti-inflammatory drugs) or vitamins.

Parents or legal guardians of all study participants were required to sign written informed consent which explained the aims, design and expected outcomes of the study. The study was performed in accordance with the Declaration of Helsinki on Biomedical Research Involving Human Subjects. The study protocol and procedures were approved by the Ethics Committee of the Medical University of Bialystok (No R-I-002/144/2019).

\section{Measurements}

After the participants had rested in the sitting position for 30 minutes, blood samples were collected from peripheral veins before starting the treatment. The serum was separated by centrifugation immediately at $1.500 \times \mathrm{g}$ for 10 minutes at room temperature and sera were collected and stored at $-80{ }^{\circ} \mathrm{C}$ until measurements were obtained.

Following blood sample collection, all patients with chronic idiopathic uveitis required both topical and glucocorticosteroid (GCs) treatment (first intravenous, then oral), with a maintenance dose not exceeding $10 \mathrm{mg}$ oral prednisolone equivalent per day. Systemic GCs treatment was as short as possible with a maximum duration of two months. All patients with chronic non-infectious uveitis had GCs therapy in the past.

The concentration of ET-1 in serum was determined by sandwich enzyme-linked immunosorbent assay (ELISA) using a commercially available kit Endothelin-1 Immunoassay (R@D Systems, Inc., Minneapolis, MN, USA). ELISA kit was used following the manufacturer's instructions. Readings were performed using an ELISA microplate reader (ANTHOS, Wals/Salzburg, Austria) at an absorbance value of $450 \mathrm{~nm}$. The results were expressed in $\mathrm{pg} / \mathrm{mL}$. Sensitivity of the assay was $0.207 \mathrm{pg} / \mathrm{mL}$. The coefficients of variation values $(\mathrm{CV} \%)$ of intra-assay precision was $2.3 \%$ for $7.34 \mathrm{pg} / \mathrm{mL}$ and $1.9 \%$ for $14.7 \mathrm{pg} / \mathrm{mL}$ and inter-assay precision was $5.9 \%$ for $4.43 \mathrm{pg} / \mathrm{mL}$ and $5.3 \%$ for $14.4 \mathrm{pg} / \mathrm{mL}$.

The concentration of $\mathrm{C}$ reactive protein (CRP) in serum was determined by immunoturbidimetric method using CRP4 reagent kit (Roche Diagnostics GmbH, Mannheim, Germany). In this method, human CRP agglutinates with biologically inert latex particles coated with mouse monoclonal anti-CRP antibodies. The aggregates are determined turbidimetrically at $570 \mathrm{~nm}$. The coefficient of variation values $(\mathrm{CV} \%)$ of intra-assay precision (repeatability) were $1.7 \%$ for $3.63 \mathrm{mg} / \mathrm{L}$ and $1.3 \%$ for $9.69 \mathrm{mg} / \mathrm{L}$, and inter- assay precision (intermediate precision, 2 aliquots per run, 2 runs per day, 21 days) was $1.7 \%$ for $3.63 \mathrm{mg} / \mathrm{L}$ and $1.7 \%$ for $9.69 \mathrm{mg} / \mathrm{L}$.

All patients underwent detailed ophthalmologic examination including best corrected visual acuity measurement using Snellen Chart or illiterate E charts, intraocular pressure with TonoPen, slit-lamp examination and dilated fundus examination using Volk lens. Refractive error was determined using cycloplegic refraction after the application of $1 \%$ Tropicamide with a TONOREFTM Nidek's Auto Ref/Kerato/Tono/Pachymeter.

\section{Statistical Methods}

Statistical analysis was performed using Statistica 13 PL (StatSoft, Poland). Normality of distribution of variables was checked by the Shapiro-Wilk test. The data did not follow a normal distribution. The results were expressed as means and standard deviations (SD) and medians and quartiles (Q1, Q3), or numbers (n) and percentages (\%). Study participants were compared in regard to gender and age by the Pearson chi-square test. Differences between the study group and controls were evaluated using the Mann-Whitney $U$-test. To test differences between the location and grade of inflammation, the ANOVA rank Kruskal-Wallis test was done. Post-hoc comparisons following the ANOVA rank Kruskal-Wallis test were performed using Tukey's test. Correlations between variables were assessed by the Spearman's rank correlation coefficient. The results were considered to be statistically significant when $p$ values were lower than 0.05 .

\section{Results}

Seventeen Caucasian individuals ( 7 females, 10 males) with the mean age of $12.3 \pm 4.3$ years, aged from 5 to 17 years, with chronic non-infectious uveitis and 22 ageand gender-matched healthy subjects with the mean age of $11.6 \pm 4.5$ years, aged from 4 to 17 years, were recruited for the study. Best corrected visual acuity of the eye with inflammation ranged from 0.7 to 0.9 . Subjects from the control group had full visual acuity and did not require correction. All patients with chronic uveitis and controls had normal intraocular pressure of $14-18 \mathrm{mmHg}$.

The basic characteristics of idiopathic uveitis patients and controls are summarized in Table 2. Statistically significant difference between ET-1 concentration in patients with chronic idiopathic uveitis and controls was observed $(\mathrm{p}=0.008)$ (Figure 1). In chronic idiopathic uveitis, the range of ET-1 was very narrow and ranged from $0.86 \mathrm{pg} /$ 
Table 2 Basic Characteristics and Serum Endothelin-I Concentration in Children and Adolescents with Idiopathic Uveitis and Control Group

\begin{tabular}{|c|c|c|c|}
\hline Parameter & Chronic Idiopathic Uveitis & Control Group & $p$ values \\
\hline Number, $\mathrm{n}$ & 17 & 22 & \\
\hline Age, years & $12.3 \pm 4.30$ & $11.6 \pm 4.46$ & 0.581 \\
\hline Gender (female/male), n (\%) & $7(4 I) / 10$ (59) & II (50)/II (50) & 0.201 \\
\hline Age group ( $\leq 13 />13$ year), $n(\%)$ & $9(53) / 8(47)$ & $13(59) / 9(4 I)$ & 0.393 \\
\hline Endothelin-I, pg/mL & $1.33(1.22 ; 1.48)$ & $1.93(1.1 ; 3.11)$ & 0.008 \\
\hline
\end{tabular}

Notes: The results are presented as mean and standard deviation (SD) and medians and quartiles (QI; Q3), or numbers (n) and percentages (\%).

$\mathrm{mL}$ to $1.56 \mathrm{pg} / \mathrm{mL}$. In controls, the value range of ET-1 concentration was wider and extended from $0.33 \mathrm{pg} / \mathrm{mL}$ to $3.83 \mathrm{pg} / \mathrm{mL}$. In further analysis the relationship between ET-1 concentrations and participant characteristics were assessed in subgroups, taking into account gender and age group $(\leq 13 />13$ years of age). No significant differences were found in ET-1 levels between the genders and age groups, either in uveitis patients $(p=0.807 ; p=0.961$, respectively) or controls ( $p=0.646 ; p=0.504$, respectively). No correlations were established between ET-1 concentration and age, either in idiopathic uveitis patients or controls $(r=-0.070, p=0.789$ and $r=-0.257, p=$ 0.248 , respectively).

Characteristics of chronic idiopathic uveitis patients are presented in Table 3. All chronic idiopathic uveitis patients presented an insidious onset and persistent duration. The mean age at onset of patients with chronic uveitis was $11.7 \pm 4.3$ years, mean follow-up period (treatment duration) $111 \pm 13.7$ days and disease duration $202 \pm 62.6$ days. CRP concentration

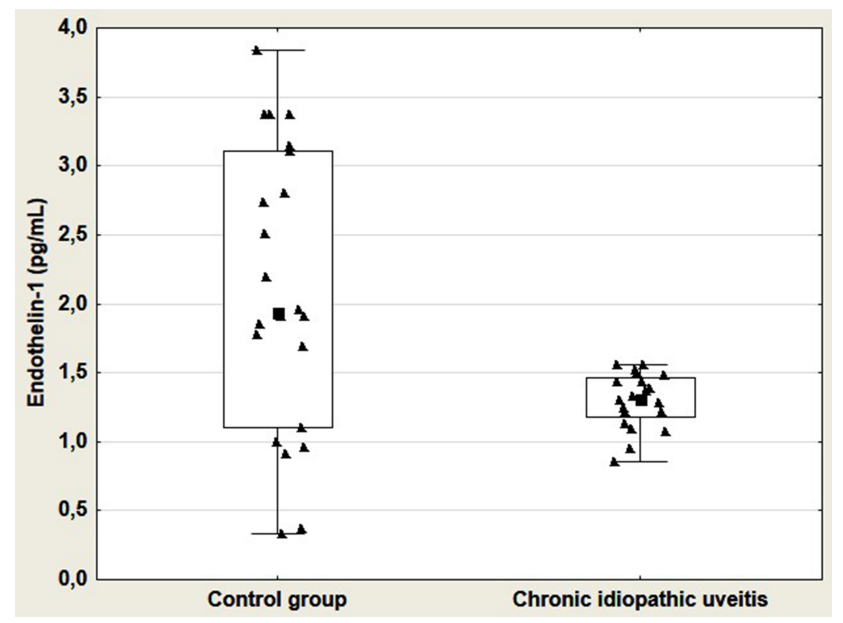

Figure I Box and whisker plots and scatter plots of serum endothelin-I concentrations in control group and chronic idiopathic uveitis. Boxes represent the interquartile range (25th-75th percentiles), the point in the box represents the median, and the whiskers extend to the most extreme data points (range). in all patients with chronic uveitis was within a normal range (up to $5 \mathrm{mg} / \mathrm{L}$ ) with median (Q1; Q3) $0.6(0.3 ; 0.9) \mathrm{mg} / \mathrm{L}$. In the study cohort, no differences were established in ET-1 concentrations between uveitis patients with different best visual acuity: 0.7, 0.8 and 0.9 [medians (Q1; Q3): 1.30 $(0.95 ; 1.39)$ vs $1.37(1.22 ; 1.44)$ vs $1.39(1.15 ; 1.54) \mathrm{pg} / \mathrm{mL}$; $H=1.102, p=0.576]$. There were no correlations between the levels of ET-1 and CRP $(r=-0.118, p=0.651)$, between ET-1 levels, and the best corrected visual acuity and intraocular pressure of the eye with inflammation $(r=0.259, p=0.315$ and $r=0.186, p=0.475$, respectively)

Nine out of 17 patients participating in the study presented with anterior uveitis, 5 - posterior uveitis and 3 - panuveitis; 16 with unilateral and 1 with bilateral laterality. Considering the location of inflammation, there were no differences between ET-1 concentrations in anterior uveitis, posterior uveitis and panuveitis [medians (Q1; Q3): 1.37 (1.28; 1.48) vs $1.22(0.95 ; 1.39)$ vs $1.33(1.22 ; 1.50) \mathrm{pg} / \mathrm{mL} ; H=0.912, p=$ 0.634 , respectively]. No significant differences in ET-1 concentrations between chronic idiopathic uveitis patients with varying grades of inflammation were observed (Table 4).

\section{Discussion}

In our study, we observed significantly lower ET-1 concentration in patients with chronic idiopathic uveitis in comparison to controls. We concluded that ET-1 expression is disturbed in chronic idiopathic uveitis irrespective of anatomical location and grade of inflammation. The significantly lower concentration of ET-1 observed in both females and males may indicate dysregulation in the endothelin signaling pathway and may be considered a predictive factor for long-term structural damage of ocular tissues. Our study is the first to demonstrate lower levels of ET-1 in chronic non-infectious uveitis and therefore we are unable to compare our results with those of other authors. Studies on uveitis have been performed in patients with rheumatological diseases associated with uveitis and on induced animal models of uveitis. The most common type of 
Table 3 Characteristics of Chronic Idiopathic Uveitis Patients and the Grades of Inflammation According to SUN Criteria

\begin{tabular}{|c|c|c|c|c|c|c|c|c|}
\hline Age & $\begin{array}{l}\text { Sex } \\
\text { (F/M) }\end{array}$ & $\begin{array}{l}\text { Visual Acuity } \\
\text { (R/L) }\end{array}$ & $\begin{array}{l}\text { Anatomical } \\
\text { Location }\end{array}$ & $\begin{array}{l}\text { Anterior } \\
\text { Chamber Cells }\end{array}$ & $\begin{array}{l}\text { Anterior } \\
\text { Chamber Flare }\end{array}$ & $\begin{array}{l}\text { Vitreous } \\
\text { Haze }\end{array}$ & $\begin{array}{l}\text { CRP, mg/ } \\
\text { L }\end{array}$ & $\begin{array}{l}\text { ET-I, pg/ } \\
\mathrm{mL}\end{array}$ \\
\hline 15 & $M$ & $1.0 / 0.9$ & A & $0.5+$ & $1+$ & & 0.2 & 1.56 \\
\hline 17 & $\mathrm{~F}$ & $0.9 / 1.0$ & $P$ & & & I & 0.6 & 1.56 \\
\hline 7 & $M$ & $0.8 / 1.0$ & A & $0.5+$ & $1+$ & & 0.88 & 1.44 \\
\hline 17 & $M$ & $0.9 / 1.0$ & A & $0.5+$ & I+ & & 0.3 & 1.3 \\
\hline 11 & $\mathrm{~F}$ & $1.0 / 0.8$ & $A+P$ & $1+$ & $1+$ & I & 0.3 & 1.22 \\
\hline 16 & $M$ & $0.7 / 1.0$ & $P$ & & & I & 0.3 & 0.86 \\
\hline 17 & $\mathrm{~F}$ & I.0/0.7 & $A+P$ & $1+$ & $2+$ & I & 0.6 & 1.33 \\
\hline 9 & $\mathrm{~F}$ & $1.0 / 0.9$ & A & $0.5+$ & $1+$ & & 0.1 & 1.52 \\
\hline 15 & $\mathrm{~F}$ & $1.0 / 0.9$ & A & $0.5+$ & $1+$ & & 0.9 & 1.09 \\
\hline 10 & $M$ & $0.7 / 1.0$ & $P$ & & & 2 & 0.2 & 1.39 \\
\hline 17 & $M$ & I.0/0.7 & $P$ & & & 2 & 0.5 & 0.95 \\
\hline 8 & $M$ & $0.9 / 0.9$ & $P$ & & & I & 1.3 & 1.22 \\
\hline 13 & $M$ & $1.0 / 0.8$ & A & $1+$ & $2+$ & & 0.5 & 1.37 \\
\hline 13 & $\mathrm{~F}$ & I.0/0.7 & $A$ & $1+$ & $2+$ & & 3.08 & 1.28 \\
\hline 15 & $M$ & I.0/0.7 & $A+P$ & $1+$ & $1+$ & 1 & 0.91 & 1.5 \\
\hline 5 & $\mathrm{~F}$ & I.0/0.9 & A & $0.5+$ & $1+$ & & 0.79 & 1.07 \\
\hline 5 & $M$ & $0.9 / 1.0$ & A & $0.5+$ & $1+$ & & 3.8 & 1.48 \\
\hline
\end{tabular}

Abbreviations: A, anterior uveitis; A+P, panuveitis; CRP, C reactive protein; ET-I, endothelin-I; F, female; L, left; M, male; P, posterior uveitis; R, right; SUN, the Standardization of Uveitis Nomenclature.

Table 4 Concentrations of Endothelin-I Depending on the Grade of Inflammation

\begin{tabular}{|l|l|l|l|}
\hline Grade of Inflammation & \multicolumn{2}{|l|}{ ET-I, pg/mL } & p values \\
\hline Number & 7 & 5 & \\
Anterior chamber cells (grade 0.5+ vs I+) & $1.44(I . I ; 1.52)$ & $1.33(1.28 ; 1.37)$ & 0.745 \\
Number & 9 & 3 & \\
Anterior chamber flare (grade I+ vs 2+) & $1.44(1.22 ; 1.50)$ & $1.33(1.28 ; 1.37)$ & 0.711 \\
Number & 6 & 2 & 0.868 \\
Vitreous haze (grade I vs 2) & $1.27(1.22 ; 1.50)$ & $1.17(0.95 ; 1.39)$ & \\
\hline
\end{tabular}

Note: The results are presented as medians and quartiles (QI; Q3).

Abbreviation: ET-I, endothelin-I.

idiopathic uveitis in our study cohort was anterior chronic uveitis with an insidious onset and persistent duration, as confirmed by the reports of other authors. 3,4

ET-1 modulates pericyte contractility to regulate retinal blood flow and is involved in the regulation of intraocular pressure and aqueous humor dynamics. ${ }^{17,18}$ An amount of blood needed in various organs and tissues varies and is achieved by adapting perfusion pressure and local resistance to flow. The blood flow in various tissues in the eye is regulated differently. ${ }^{26}$ The eye is supplied by two vascular systems: the uveal and the retinal vessels. The retinal blood flow is characterized by a low perfusion rate, a high vascular resistance and a high oxygen extraction. By contrast, the choroid blood flow shows a high perfusion rate, a low vascular resistance and a low oxygen extraction. Vascular dysregulation (VD) plays a significant role in the pathogenesis of uveitis. Patients with primary VD tend to have signs of oxidative stress and a slightly increased ET-1 plasma level. The secondary VD occurs in the case of autoimmune disorders in different diseases. ${ }^{27}$

The human serum level of ET-1 has a low but measurable concentration of $0.7-5.0 \mathrm{pg} / \mathrm{mL}^{28,29}$ and is characterized by a very short half-life in the blood - around 7 minutes. Low concentration in the blood results from active uptake by receptors present in epithelial cells and high activity of the endothelin-degrading enzyme. In turn, attachment of the endothelin to the receptor and the subsequent internalization of the receptor-ligand complex to the cytosol, protects it from biodegradation and prolongs this time. ${ }^{30,31}$ So, the concentration of ET-1 in plasma depends on several elements as synthesis, connection with receptors and the efficiency of mechanisms eliminating from the body in the lungs, kidneys and liver. ${ }^{32}$ It should be noted that hypoxia is a strong 
stimulator of ET-1 in vivo and in vitro, since the concentration of this peptide in the blood of people with hypoxaemic cor pulmonale is the same as in healthy volunteers during short-term hypoxaemia. ${ }^{33,34}$

There is increasing evidence that the endothelin signaling pathway plays a key role in the pathogenesis of several ocular diseases. But only two studies presented lower expression of ET-1, in adult patients with retinitis pigmentosa $^{35}$ and in children with high myopia with the axial length of the eye $>26 \mathrm{~mm}^{36}$

In our study, patients with chronic idiopathic uveitis had significantly lower ET-1 concentrations in comparison to control subjects. In all chronic uveitis patients, ET-1 levels were almost at the same level within a very narrow range. Disturbance of the endothelin signaling pathway can play a key role in permanent visual impairment in patients with chronic idiopathic uveitis. ${ }^{37}$ Low concentration of ET-1 may lead to decreased blood flow in the choroidal vessels by effecting in reversing the balance between ET-1 and nitric oxide (NO) concentration. In chronic inflammation the balance between vasoconstriction and vasodilatation factors is disturbed in favor of vasoconstriction. ${ }^{31}$ This condition is also sometimes referred to as "NO deficiency" because NO is the main factor responsible for maintaining proper vascular tone. Consequently, the production of pro-thrombotic and inflammatory factors by the endothelium increases which initiates a sequence of events that ultimately leads to tissue damage. ${ }^{38}$

Several studies have demonstrated that ET-1 contributes to the development of inflammatory processes in the vascular wall. It has been shown that ET-1 is associated with an inflammatory response involving activation of transcription factors, such as nuclear factor $(\mathrm{NF}-\kappa \mathrm{B})$ and expression of proinflammatory cytokines, including tumor necrosis factor alfa (TNF- $\alpha$ ), interleukin-1 (IL-1) and IL-6. ${ }^{39}$ In turn, these transcription factors and proinflammatory cytokines can stimulate ET-1 production. ${ }^{40}$ IL-33, a crucial member of the IL1 family, is considered a dual function protein which exerts its pro- or anti-inflammatory effect by acting as both an intracellular nuclear factor and a cytokine. ${ }^{41}$ ET-1 increases the expression of soluble IL-33 receptors (sST2, suppression of tumorigenicity 2 receptors) which may prevent binding of IL-33 to cell-surface receptors.

Epithelium responds to various environmental factors by releasing key cytokines such as thymic stromal lymphopoietin (TSLP), IL-33 and IL-25, ${ }^{42}$ cytokines regarded as type 2 immune response-initiating. ${ }^{43}$ The IL-33/ST2 axis could affect cells both of the innate and adaptive immune system. ${ }^{44}$ Many studies have demonstrated recently that the
IL33/ST2 axis plays crucial role in several eye diseases, including uveitis. ${ }^{45}$ IL-33 was significantly upregulated in autoimmune uveitis in mice ${ }^{46}$ and in patients with Behçet's uveitis. ${ }^{47}$ However, no differences in IL-33 levels in either serum or aqueous humor were observed between acute anterior uveitis and controls. ${ }^{48}$ Future investigations should reevaluate the role of IL-33/ST2 in different types of uveitis, compare differences between infectious and noninfectious uveitis and clarify potential reasons for the discrepancy.

The use of GCs especially in general are the primary treatment choice in patients with chronic idiopathic uveitis but it is associated with a multiple number of side effects in the eye. ${ }^{49-52}$ The most common complication after local GCs use is increased intraocular pressure and cataract development. ET-1 synthesis in human cells is regulated at the transcription level and GCs may reduce gene expression. ${ }^{53}$ GCs reduce prostaglandin $\mathrm{E}$ accumulation in rabbit eyes by limiting the availability of the substrate for prostaglandin and leukotrienes biosynthesis and thus suppress the inflammatory response. ${ }^{54}$ Keles et al showed that dexamethasone reduced intraocular inflammation by lowering levels of inducible nitric oxide synthase (iNOS) and TNF- $\alpha$ expression in rat model of endotoxin-induced uveitis. $^{23}$ It has been reported that budesonide given subcutaneously reduced ET-1 level by $72 \%$ in induced bronchial asthma rats. ${ }^{55}$ Tseĭmakh et al also have observed significantly reduced ET-1 levels in chronic obstructive pulmonary disease patients treated with systemic and inhaled GCs. ${ }^{56}$ Given the mechanism of action of GCs and their influence on ET-1 expression, the question arises whether their use in children and adolescents with chronic idiopathic uveitis can bring good results or lead to tissue damage. It is difficult to say whether the ET-1 concentration was lower initially in chronic non-infectious uveitis or was it the result of the GCs used in the past.

The two major limitations of our study were the small sample size and the observational design of the study. This did not allow us to draw firm conclusions about causality. In addition, the inability to assess the concentration of factors known to promote the expression and inhibitors of ET-1 and proinflammatory cytokines in this study may limit the spectrum of possible associations. In connection with the role that inflammation plays in tissue damage and the development of undesirable symptoms, new methods of controlling the inflammatory response are constantly being sought. However, further studies involving a larger number of participants and longer follow-up duration are required to confirm our results. 


\section{Conclusions}

ET-1 expression is disturbed in pediatric chronic idiopathic uveitis irrespective of the anatomical location and grade of inflammation. We conclude that lower ET-1 expression plays a crucial role in disturbed vascular tone control and can result in permanent visual impairment in chronic noninfectious uveitis.

\section{Abbreviations}

AAU, acute anterior uveitis; ET-1, endothelin-1; ETA, endothelin receptor A; ETB, endothelin receptor B; GCs, glucocorticosteroids; IL, interleukin; NO, nitric oxide; NF, nuclear factor; SUN, Standardization of Uveitis Nomenclature; ST2, suppression of tumorigenicity 2; TNF, tumor necrosis factor; TSLP, thymic stromal lymphopoietin; VD, vascular dysregulation; VSMC, vascular smooth muscle cells.

\section{Data Sharing Statement}

The original data used to support the findings of this study are available from the corresponding authors upon request.

\section{Acknowledgments}

We would like to thank the Pediatric University Hospital in Bialystok for assistance in conducting the study. This study was supported but not funded by the Medical University of Bialystok.

\section{Disclosure}

The authors declare that they have no conflicts of interest.

\section{References}

1. Standardization of Uveitis Nomenclature (SUN) Working Group. Standardization of uveitis nomenclature for reporting clinical data Results of the First International Workshop. Am $J$ Ophthalmol. 2005;140(3):509-516.

2. Deschenes J, Murray PI, Rao NA, Nussenblatt RB. International Uveitis Study Group (IUSG): clinical classification of uveitis. Ocul Immunol Inflamm. 2008;16(1):1-2. doi:10.1080/09273940801899822

3. Tugal-Tutkun I. Pediatric uveitis. J Ophthalmic Vis Res. 2011;6 (4):259-269.

4. Chan NS-W, Choi J, Cheung CMG. Pediatric uveitis. Asia Pac J Ophtalmol (Phia). 2018;7(3):192-199.

5. Paivönsalo-Hietanen T, Tuominen J, Saari KM. Uveitis in children: population-based study in Finland. Acta Ophthalmol Scand. 2000;78 (1):84-88. doi:10.1034/j.1600-0420.2000.078001084.x

6. Edelsten C, Reddy MA, Stanford MR, Graham EM. Visual loss associated with pediatric uveitis in English primary and referral centers. Am J Ophthalmol. 2003;135(5):676-680. doi:10.1016/S0002-9394(02) 02148-7

7. Mesquida M, Molins B, Llorenç V, et al. Proinflammatory cytokines and C-reactive protein in uveitis associated with Behçet's disease. Mediators Inflamm. 2014;2014:396204.
8. García-De-Vicuña C, Díaz-Llopis M, Salom D, et al. Usefulness of adalimumab in the treatment of refractory uveitis associated with juvenile idiopathic arthritis. Mediators Inflamm. 2013;2013:560632. doi:10.1155/2013/560632

9. Sen ES, Dick AD, Ramanan AV. Uveitis associated with juvenile idiopathic arthritis. Nat Rev Rheumatol. 2015;11(6):338-348.

10. Rosenbaum JT. Uveitis: an internist's view. Arch Intern Med. 1989;149(5):1173-1176. doi:10.1001/archinte.1989.00390050129026

11. Rosenbaum JT. Nibbling away at the diagnosis of idiopathic uveitis. JAMA Ophthalmol. 2015;133(2):146-147. doi:10.1001/ jamaophthalmol.2014.4272

12. Kaiser PK, Lowder CY, Sullivan P, et al. Chest computerized tomography in the evaluation of uveitis in elderly women. $A m$ $J$ Ophthalmol. 2002;133(4):499-505. doi:10.1016/S0002-9394(02) 01333-8

13. de Groot-mijnes JD, de Visser L, Zuurveen S, et al. Identification of new pathogens in the intraocular fluid of patients with uveitis. Am $J$ Ophthalmol. 2010;150(5):628-636. doi:10.1016/j. ajo.2010.05.015

14. Jain A. Endothelin-1-induced endoplasmic reticulum stress in disease. J Pharmacol Exp Ther. 2013;346(2):163-172. doi:10.1124/ jpet.113.205567

15. Yanagisawa M, Kurihara H, Kimura S, et al. A novel potent vasoconstrictor peptide produced by vascular endothelial cells. Nature. 1988;332(6163):411-415. doi:10.1038/332411a0

16. Hynynen MM, Khalil RA. The vascular endothelin system in hypertension-recent patents and discoveries. Recent Pat Cardiovasc Drug Discov. 2006;1(1):95-108. doi:10.2174/ 157489006775244263

17. Kawamura H, Oku H, Li Q, Sakagami K, Puro DG. Endothelininduced changes in the physiology of retinal pericytes. Invest. Ophthalmol Vis Sci. 2002;43(3):882-888.

18. Taniguchi T, Okada K, Haque MS, Sugiyama K, Kitazawa Y. Effects of endothelin-1 on intraocular pressure and aqueous humor dynamics in the rabbit eye. Curr Eye Res. 1994;13(6):461-464.

19. Shoji N, Oshika T, Masuda K. Endothelin-1 and intraocular inflammation in pigmented rabbit eyes. Jpn J Ophthalmol. 1997;41 (3):150-153. doi:10.1016/S0021-5155(97)00032-4

20. Er H, Evereklioglu C, Cumurcu T, et al. Serum homocysteine level is increased and correlated with endothelin-1 and nitric oxide in Behçet's disease. Br J Ophthalmol. 2002;86(6):653-657.

21. Shoji N, Oshika T, Masuda K. [Endothelin-1 and intraocular inflammation in pigmented rabbit eyes]. Nippon Ganka Gakkai Zasshi. 1995;99(6):631-635

22. Shoji N, Oshika T, Amano S, Masuda K. Effects of endothelin receptor antagonists on anterior chamber inflammation induced by intravitreal injection of endothelin-1. Exp Eye Res. 1999;69 (4):437-444. doi:10.1006/exer.1999.0721

23. Keles S, Halici Z, Atmaca HT, et al. The ocular endothelin system: a novel target for the treatment of endotoxin-induced uveitis with bosentan. Invest Ophthalmol Vis Sci. 2014;55(6):3517-3524. doi:10.1167/iovs.14-14193

24. Nussenblatt RB, Palestine AG, Chan CC, et al. Standardization of vitreal inflammatory activity in intermediate and posterior uveitis. Ophthalmology. 1985;92:467-471. doi:10.1016/S0161-6420(85) 34001-0

25. Zierhut M, Deuter C, Murray FI. Classification of Uveitis - Current Guidelines. European Ophthalmic Review. 2007;77-78.doi:10.17925/ EOR.2007.00.00.77

26. Kur J, Newman EA, Chan-Ling T. Cellular and physiological mechanisms underlying blood flow regulation in the retina and choroid in health and disease. Prog Retin Eye Res. 2012;31(5):377-406. doi:10.1016/j.preteyeres.2012.04.004

27. Flammer J, Konieczka K, Flammer AJ. The primary vascular dysregulation syndrome: implications for eye diseases. EPMA J. 2013;4 (1):14. 
28. Predel HG, Meyer-Lehnert H, Bäcker A, Stelkens H, Kramer HJ. Plasma concentrations of endothelin in patients with abnormal vascular reactivity. Effects of ergometric exercise and acute saline loading. Life Sci. 1990;47(20):1837-1843. doi:10.1016/00243205(90)90286-Z

29. Shichiri M, Hirata Y, Ando K, et al. Postural change and volume expansion affect plasma endothelin levels. JAMA. 1990;263(5):661. doi:10.1001/jama.1990.03440050055027

30. Warner TD, Battistini B, Doherty AM, Corder R. Endothelin receptor antagonists: actions and rationale for their development. Biochem Pharmacol. 1994;48(4):625-635. doi:10.1016/0006-2952(94)90038-8

31. Marini M, Carpi S, Bellini A, Patalano F, Mattoli S. Endothelin-1 induces increased fibronectin expression in human bronchial epithelial cells. Biochem Biophys Res Commun. 1996;220(3):896-899. doi:10.1006/bbrc.1996.0502

32. Kohno M, Murakawa K, Yasunari K, et al. Prolonged blood pressure elevation after endothelin administration in bilaterally nephrectomized rats. Metabolism. 1989;38(8):712-713. doi:10.1016/00260495(89)90054-1

33. Cargill RI, Kiely DG, Clark RA, Lipworth BJ. Hypoxaemia and release of endothelin-1. Thorax. 1995;50(12):1308-1310. doi:10.1136/thx.50.12.1308

34. Ferri C, Bellini C, De Angelis C, et al. Circulating endothelin-1 concentrations in patients with chronic hypoxia. J Clin Pathol. 1995;48(6):519-524. doi:10.1136/jcp.48.6.519

35. Ohguro H, Mashima Y, Nakazawa M. Low levels of plasma endothelin-1 in patients with retinitis pigmentosa. Clin Ophthalmol. 2010;4:569-573. doi:10.2147/OPTH.S9152

36. Powierza K, Żelazowska-Rutkowska B, Sawicka-Powierza J, et al. Endothelin-1 serum concentration is lower in children and adolescents with high myopia, a preliminary study. J Clin Med. 2020;9 (5): 1327. doi: $10.3390 / \mathrm{jcm} 9051327$

37. Freeman BD, Machado FS, Tanowitz HB, Desruisseaux MS. Endothelin-1 and its role in the pathogenesis of infectious diseases. Life Sci. 2014;118(2):110-119. doi:10.1016/j.1fs.2014.04.021

38. Masaki T, Yanagisawa M, Inoue A, Kimura S, Goto K. Study on the endothelin gene and its expression. Jpn Circ J. 1990;54 (9):1221-1225. doi:10.1253/jcj.54.1221

39. Yeager ME, Belchenko DD, Nguyen CM, et al. Endothelin-1, the unfolded protein response, and persistent inflammation: role of pulmonary artery smooth muscle cells. Am J Respir Cell Mol Biol. 2012;46:14-22. doi:10.1165/rcmb.2010-0506OC

40. Virdis A, Schiffrin EL. Vascular inflammation: a role in vascular disease in hypertension? Curr Opin Nephrol Hypertens. 2003;12:181-187.

41. Abd Rachman Isnadi MF, Chin VK, Abd Majid R, et al. Critical roles of IL-33/ST2 pathway in neurological disorders. Mediators Inflamm. 2018;2018:5346413. doi:10.1155/2018/5346413

42. Divekar R, Kita H. Recent advances in epithelium-derived cytokines (IL-33, IL-25, and thymic stromal lymphopoietin) and allergic inflammation. Curr Opin Allergy Clin Immunol. 2015;15(1):98-103. doi:10.1097/ACI.0000000000000133
43. Schmitz J, Owyang A, Oldham E, et al. IL-33, an interleukin-1-like cytokine that signals via the IL-1 receptor-related protein ST2 and induces $\mathrm{T}$ helper type 2-associated cytokines. Immunity. 2005;23 (5):479-490. doi:10.1016/j.immuni.2005.09.015

44. Cayrol C, Girard JP. Interleukin-33 (IL-33): a nuclear cytokine from the IL-1 family. Immunol Rev. 2018;281(1):154-168. doi:10.1111/ imr. 12619

45. Qian Y, Zhang M. The functional roles of IL-33/ST2 axis in ocular diseases. Mediators Inflamm. 2020;2020:5230716. doi:10.1155/2020/ 5230716

46. Barbour M, Allan D, Xu H, et al. IL-33 attenuates the development of experimental autoimmune uveitis. Eur $J$ Immunol. 2014;44 (11):3320-3329. doi:10.1002/eji.201444671

47. Koca SS, Kara M, Deniz F, et al. Serum IL-33 level and IL-33 gene polymorphisms in Behçet's disease. Rheumatol Int. 2015;35 (3):471-477. doi:10.1007/s00296-014-3111-2

48. Zhao B, Chen W, Jiang R, et al. Expression profile of IL-1 family cytokines in aqueous humor and sera of patients with HLA-B27 associated anterior uveitis and idiopathic anterior uveitis. Exp Eye Res. 2015;138:80-86. doi:10.1016/j.exer.2015.06.018

49. Bierly JR, Nozik RA. Management of uveitis. Curr Opin Ophthalmol. 1992;3(4):527-533. doi:10.1097/00055735-19920800000015

50. de Vos AF, van Haren MA, Verhagen C, Hoekzema R, Kijlstra A. Kinetics of intraocular tumor necrosis factor and interleukin-6 in endotoxin-induced uveitis in the rat. Invest Ophthalmol Vis Sci. 1994;35(3):1100-1106.

51. de Vos AF, Hoekzema R, Kijlstra A. Cytokines and uveitis, a review. Curr Eye Res. 1992;11(6):581-597. doi:10.3109/02713689209001814

52. Schnabel A, Unger E, Brück N, et al. High-dose intravenous methylprednisolone in juvenile non-infectious uveitis: a retrospective analysis. Clin Immunol. 2019;211:108327. doi:10.1016/j.clim.201 9.108327

53. Calderón E, Gómez-Sánchez CE, Cozza EN, et al. Modulation of endothelin-1 production by a pulmonary epithelial cell line. I. Regulation by glucocorticoids. Biochem Pharmacol. 1994;48 (11):2065-2071.

54. Floman N, Zor U. Mechanism of steroid action in ocular inflammation: inhibition of prostaglandin production. Invest Ophthalmol Vis Sci. 1977;16(1):69-73.

55. Andersson SE, Zackrisson C, Hemsén A, Lundberg JM. Regulation of lung endothelin content by the glucocorticosteroid budesonide. Biochem Biophys Res Commun. 1992;188(3):1116-1121. doi:10.1016/0006291X(92)91347-S

56. Tseimmakh I, Momot AP, Kostiuchenko GI, et al. Role of endothelial dysfunction, the interface between hemostatic and system inflammatory responses in the pathogenesis of an infectious inflammation-dependent exacerbation of chronic obstructive pulmonary disease. Ter Arkh. $2013 ; 85(3): 17-22$
Clinical Ophthalmology

\section{Publish your work in this journal}

Clinical Ophthalmology is an international, peer-reviewed journal covering all subspecialties within ophthalmology. Key topics include: Optometry; Visual science; Pharmacology and drug therapy in eye diseases; Basic Sciences; Primary and Secondary eye care; Patient Safety and Quality of Care Improvements. This journal is indexed on PubMed
Central and CAS, and is the official journal of The Society of Clinical Ophthalmology (SCO). The manuscript management system is completely online and includes a very quick and fair peer-review system, which is all easy to use. Visit http://www.dovepress.com/ testimonials.php to read real quotes from published authors.

\section{Dovepress}

